\title{
Sclerotherapy of Hydroceles and Spermatoceles with Alcohol: Results and Effects on the Semen Analysis
}

\author{
Chen Jen Shan, Antonio Marmo Lucon, Rodrigo Pagani, Miguel Srougi \\ Division of Urology, Department of Surgery, Hospital das Clínicas, Medical School, University of \\ São Paulo, São Paulo, Brazil
}

\begin{abstract}
Purpose: To evaluate the success rates of sclerotherapy of the tunica vaginalis with alcohol for the treatment of hydroceles and/or spermatoceles, as well as, evaluation of pain, formation of hematomas, infection and its effects in spermatogenesis .

Materials and Methods: A total of 69 patients, with offsprings and diagnosis of hydrocele and/or spermatocele, were treated during the period from April 2003 to June 2007. Semen analysis was obtained from patients who were able to provide us with samples. The sclerotherapy with alcohol at $99.5 \%$ was undertaken as outpatient procedure.

Results: The average volume drained pre-sclerotherapy was $279.82 \mathrm{~mL}$ (27 to 1145). The median follow-up was 43 months ( 9 to 80 ). A total of 114 procedures were performed on 84 units, with an average of 1.35 procedures / unit and an overall success rate of $97.62 \%$. Of the 69 patients, $7(10.14 \%)$ reported minor pain immediately after the procedure, $3(4.35 \%)$ moderate pain and $2(2.89 \%)$ intense pain. Post-Sclerotherapy spermograms revealed reduction of the parameters regarding: concentration, motility and morphology up to 6 months post procedure, with return to normal parameters 12th months after procedure.

Conclusions: Sclerotherapy of hydroceles and spermatoceles with $99.5 \%$ alcohol is an efficient procedure that can be perormed without difficulties, cost-effectiveness, with few side effects and which may be performed in patients who wish fertility.
\end{abstract}

Key words: Testis; hydrocele; spermatocele; sclerotherapy; alcohol; spermatogenesis

Int Braz J Urol. 2011; 37: 307-313

\section{INTRODUCTION}

Sclerotherapy has been gaining wider acceptance for the treatment of hydroceles, because of less invasive nature, low morbidity, with faster recovery time. Many different substances have been used as sclerosing agents in the treatment of hydroceles, with variable success rates and side effects (1-4).

Alcohol is easily acquired agent and it has been used as sclerosing agent for renal cysts, liver and thyroid for over two decades, achieving cure rates over $95 \%$, with few side effects and no systemic toxicity. (5-7). Juliano et al. (8) reported use of alcohol as sclerosing agent in hydroceles with a
$100 \%$ success rate and complain of pain in $26.6 \%$ of cases even with testicular cord block with local anesthesia. However, effects if abnormalities in spermatogenesis has not been studied.

In this current study, we report the success rate of sclerotherapy of the tunica vaginalis with alcohol for the treatment of hydroceles and spermatoceles, as well as, evaluation of pain, formation of hematomas, infection and its effects in spermatogenesis .

\section{MATERIALS AND METHODS}

A total of 75 patients, with children, with diagnosis of hydrocele or spermatocele, were 
evaluated during April 2003 to June of 2007. The diagnosis was done by clinical examination and confirmed by scrotal ultrasonography. Of the 75 patients, 6 were excluded from the study, 5 for lack of follow-up and one death from procedure nonrelated cause.

The study included 69 pacients. The mean age was 61 y.o. (28-86 y.o.). Eleven pacients had bilateral hydroceles, three had hydrocele and spermatocele on the same side and one patient had 2 hydroceles on the same side, totaling 84 units, 49 on the right and 35 on the left.

Of the 84 units treated, one patient had prior varicocelectomy, two had prior ipsilateral inguinal hernia repair, six had history of scrotal injury and 4 underwent open hydrocelectomy.. Semen analysis was analized from patients who were able to provide them before treatment.

Sclerotherapy was performed on an outpatient basis with the patient in normal clothing and without shaving. The patients were placed supine. The puncture area was identified by transillumination of the scrotum avoiding blood vessels. Patients was prepped with polyvinylpyrrolidone iodine and local anesthesia performed with $2 \%$ lidocaine hydrochloride without epinephrine. Hydroceles and spermatoceles were drained with a 16 gauge angiocatheter, connected to sterile intravenous tubing per gravity. Gentle manipulation of the scrotum resulted in the total emptying of the hydrocele. In cases when the color of the drainage was not tipical yellow/straw, samples of the fluid were sent for cytologyl to rule out malignancy. Immediatly after drainage, chloridrate of lidocaine at $2 \%$ was injected into the cavity between the vaginal tunics, in the proportion of $1 \%$ of the volume drained, up to a maximum of $10 \mathrm{~mL}$ to prevent pain due to the sclerotherapy,.

The sclerosing agent used was $99.5 \%$ alcohol. The volume injected was calculated to be $10 \%$ of the volume drained from the hydrocele. The maximum volume injected was of $50 \mathrm{~mL}$ of alcohol.

After the withdrawal of the angiocatheter, the site of the puncture was compressed for $5 \mathrm{~min}$ utes and the patient was discharged with a scrotal support. No analgesics or antibiotics were used.
The patients were clinically evaluated and semen analizis was collected from patients who were able to ejaculate at 1, 3, 6 and 12 months and annually after the sclerotherapy procedure. The cases of acute total relapse within 1 month post-ptocedure underwent a repeat sclerotherapy. The cases of partial relapse were managed conservatively ascertaining reduction of overallvolume. The cases of late relapse (after 1 month of the procedure) underwent a repeat sclerotherapyat the end of the third month post recurrence.

The following were studied:

- The percentage relapse of the hydrocele after one or more sclerotherapy;

- changes in the spermogram;

- evaluation of post-procedure complications, including, pain, incidence of hematomas, local infection and faster recovery.

\section{Analysis of the Data}

A variance analysis for repetitive measures (ANOVA) was used to analyse the sperm concentration $(\mathrm{mL})$, motility, and the average Kruger's index before and after treatment at 1,3,6 and 12 months by means of Bonferroni's multiple comparisons (9).

$\mathrm{P}<0.05$ was considered significant.

\section{RESULTS}

The average volume drained at the first sclerotherapy was of $279.82 \mathrm{~mL}$ (27 to 1145). Of these, 67 samples had a yellow color, corresponding to hydrocele fluid (average volume of $277.3 \mathrm{~mL}$, varying from 27 to $1069 \mathrm{~mL} ; 7$ units with a volume greater than $500 \mathrm{~mL}$ and two units with a volume greater than $1000 \mathrm{~mL}$ ), 14 units of white color, corresponding to spermatoceles (average volume of $277.71 \mathrm{~mL}$, varying from 35 to $793 \mathrm{~mL}$; 3 units being greater than $500 \mathrm{~mL}$ ) and 3 units of blood-colored liquid (average volume of $448 \mathrm{~mL}$, varying from 56 to $1145 \mathrm{~mL}$ ).

The median follow-up was of 43 months (9 to 80$)$. 
Of the 67 units yellowish color fluid, 51 units $(76.12 \%)$ did not recur after the first application, 14 units $(20.9 \%)$ after the second, and one unit $(1.49 \%)$ after the third application. One unit was not cured even after the sixth application. Of note, ten of the 15 units that had a second application had red tinged-colored fluid on the occasion of the second puncture.

Of the 14 clear fluid units, $10(71.43 \%)$ were cured at the first application, $2(14.29 \%)$ were cured at the second and two (14.29\%) were cured at the third application. Of the four units which required a second procedure, the two which presented white fluid were cured by the second application, and the two had yellow fluid which stopped after the third procedure.

Of the three units which presented red tinged bloody fluid, two $(66 \%)$ were cured by the first application, and one required four applications.

A total of 114 procedures were undertaken on the 84 units, with an average of 1.35 procedures on each unit and an overall cure rate of $97.62 \%$.

Of the 69 patients, 7 (10.14\%) reported low intensity pain immediately after the procedure, $3(4.35 \%)$ reported moderate intensity and $2(2.89 \%)$ of high intensity pain. Analgesic (Butylescopolamine with oral Dipirone ) was given to patients. Only 2 patients with moderate pain and one who had intense pain used the medication. All patients had pain relief 20 to 30 minutes after analgesic use.

None of the cases required chord block. Eight patients (11.59\%) had low intensity pain and 1 moderate pain for a period of from 1 to 3 days. Of these, one patient took analgesic once and the other for 2 days. All patients reassumed normal activities after the procedures.

The sperm analysis before the treatment and one, three, six and twelve months after the sclerotherapy of 22 patients, are given in the Figures 1-3 and the Table-1 which follow.

We compared sperm analysis before treatment, and 1, 3, 6 and 12 months after sclerotherapy.

The sperm analysis revealed decreased parameter values for concentration, motility and strict morphology (Kruger's Index) up to the 6th months after the procedure, with no statistical sig- nificance. However, there was a return to the baseline sperm analysis parameters prior to the procedure after 12 th months from the procedure.

\section{DISCUSSION}

Hydrocelectomy is considered the gold standard for the treatment of hydroceles and remains to be the most efficient treatment modality (10), it is, however, a procedure which needs to be carried out in the operating room, often with spinal or general anesthesia, increasing the cost of care compared to sclerotherapy. Also social and medical recovery is approxinately 15 days post-

Figure 1 - Variation of sperm Concentration per $m L$ over time.

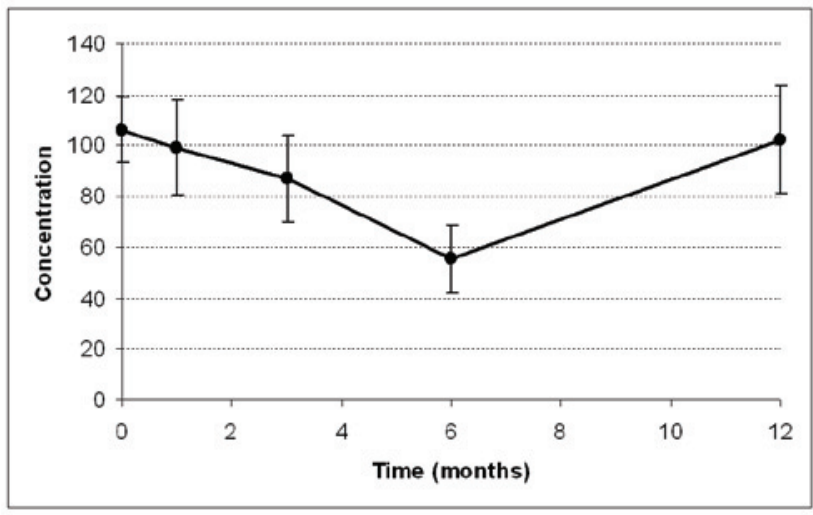

There was no statistically significance on the variation of the sperm concentration over time ( $p=0.245)$.

Figure 2 - Variation of sperm Motility over time.

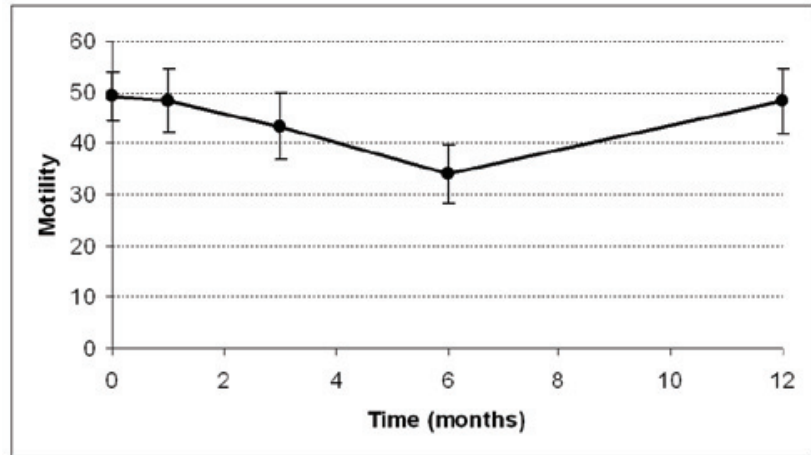

There was no statistically significance on the variation of the motility over time $(p=0.434)$. 
Figure 3 - Variation of Sperm Morphology (Kruger) over time.

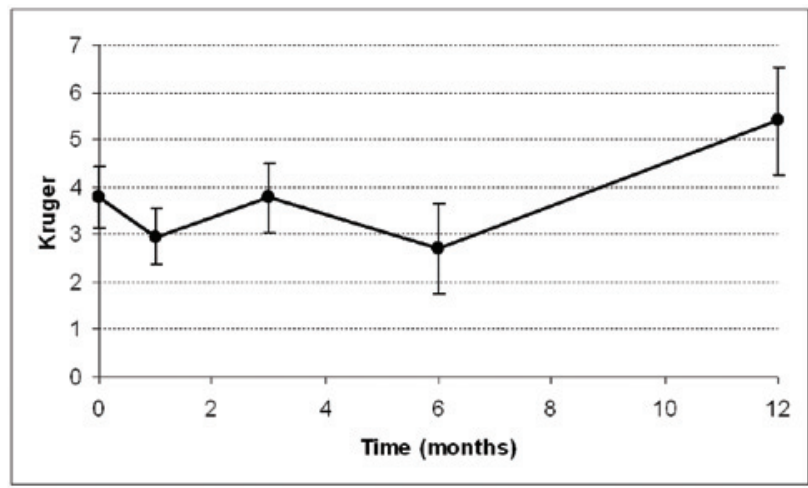

There was no statistically significance on the variation of morphology over time $(p=0.069)$.

hydrocelectomy (1). After sclerotherapy the return to normal activities is immediate (11).

The success rate after sclerotherapy varies from $20 \%(12)$ to $100 \%(2,3,8)$ depending on the sclerosing agent used. In this present study, the overall result of $98 \%$, with an average of 1.3 applications, is highly satisfactory to the patient. In a previous study using $2.5 \%$ phenol, this rate was only achieved with 1.9 applications (11).

Pain occurs in almost all cases of hydrocelectomy and may last up to a month, while with sclerotherapy it is much less frequent and depends on the agent and the method of application. Agents such as Tetracycline causes most pain, requiring hospitalization for pain management $(13,14)$. According to Juliano et al.(8), the use of alcohol resulted in slight pain in $26.6 \%$, of patients who underwent sclerotherapy and testicular cord block with $2 \%$ xylocaine,. Twelve patients $(17.39 \%)$ had pain during the procedure, $7(10.14 \%)$ defined as mild pain, $3(5.35 \%)$ moderate pain and $2(2.89 \%)$ intense pain. Of these only 3 patients ( 2 had moderate pain and 1 intense pain) took medication with Butylescopolamine with oral Dipirone. All 3 patients had relief from their pain within 20 to 30 minutes. The best effective regional anesthesia is the intra vaginal testicular block since we inhibit the sensory pain receptors in the tunica vaginalis. (15). Eight patients(11\%) had pain during the first few days after the procedure, seven had mild pain and one moderate pain for 1 to 3 days. No patients had to interrupt their daily normal activities.

Hematoma after classic hydrocelectomy was reported in up to $40 \%$ of patients in Moloney`s comparative study (1), but in modified hydrocelectomy this complication has been reduced $(16,17)$. In sclerotherapy this complication rate is much lower, varying between 0 and 5\% (18). In this present study there was no single case of hematoma. Small puncture guided by transillumination and local pressure after the procedure probably decrease the rate of this complication.

Fever reported by Yamamoto et al (3) associated with the use of OK-432 in $75 \%$ of the cases, was not seen in our patients. This side effect depends on the type of sclerosing agent used, and occurs also with the use of Etanolamine in $15 \%$ of patients (19), with sodium Tetradecyl Sulfate in up to $9 \%$ (20) and with Tetracycline in up to $7.5 \%$ (21).

Table 1 - Concentration of spermatozoids per ml, motility and Kruger's index before treatment and one, three, six and twelve months after the treatment with sclerotherapy in 22 patients. Average value and p value on each occasion in comparison with those prior to treatment.

\begin{tabular}{lccccc}
\hline & Before treatment & 1 month & 3 months & 6 months & 12 months \\
\hline Concentration & 106.22 & 99.10 & 87.20 & 55.33 & $102.33(0.985)$ \\
\multirow{2}{*}{ Motility } & & $(0.206)$ & $(0.20)$ & $(0.071)$ & \\
& 49.37 & 48.44 & 43.39 & 34.15 & 48.33 \\
Kruger's Index & \multirow{2}{*}{3.79} & $(0.695)$ & $(0.283)$ & $(0.138)$ & $0.856)$ \\
& & 2.94 & 3.78 & 2.69 & 5.40 \\
& & $(0.176)$ & $(0.454)$ & $(0.694)$ & $(0.093)$ \\
\hline
\end{tabular}


Local infection after schlerotherapy was reported by Musa18 in $12 \%$ of his cases, but no similarly high rate has been confirmed by other authors. In this present study we had no single case of infection.

The assessment of sclerosing agents on spermatogenesis is important. Studies should include patients who have offsprings. Osegbe (22) reported a reduction of $78 \%$ in the concentration of the sperm analysis 6 months after sclerotherapy of hydrocele with tetracycline. In our earlier research, in a study which compared hydrocelectomy with sclerotherapy we found a slight reduction in the concentration of sperm per milliliter at 6 th and 12th months, with no statistical significance. The reduction occurred on both groups that underwent sclerotherapy or hydrocelectomy (11). In this present study we found a reduction in the parameters up to $6 \mathrm{t}$ months, with no statistical significance, but at the 12th month these abormalities returned to baseline parameters.

\section{CONCLUSIONS}

We conclude that sclerotherapy of hydroceles and spermatoceles with $99.5 \%$ alcohol is a procedure of great efficiency, easy application, is cost-effective, with few side effects, and it may be applied to patients that desire fertitlity in the future.

\section{ABBREVIATIONS}

ML - Milliliter; \% - percent

\section{CONFLICT OF INTEREST}

None declared.

\section{REFERENCES}

1. Moloney GE: Comparison of results of treatment of hydrocele and epididymal cysts by surgery and injection. Br Med J. 1975; 3: 478-9.

2. Chen JS: Escleroterapia de hidrocele com fenol. J Bras Urol. 1998; 24: 258-60.
3. Yamamoto M, Hibi H, Miyake K: A new sclerosant therapy for testicular hydrocele with aspiration and injection of OK-432. Int Urol Nephrol. 1994; 26: 205-8.

4. Yilmaz U, Ekmekçioglu O, Tatlisen A, Demirci D: Does pleurodesis for pleural effusions give bright ideas about the agents for hydrocele sclerotherapy? Int Urol Nephrol. 2000; 32: 89-92.

5. Paananen I, Hellström P, Leinonen S, Merikanto $\mathrm{J}$, Perälä J, Päivänsalo $\mathrm{M}$, et al.: Treatment of renal cysts with single-session percutaneous drainage and ethanol sclerotherapy: long-term outcome. Urology. 2001; 57: 30-3.

6. Giorgio A, Di Sarno A, de Stefano G, Liorre G, Farella N, Scognamiglio U, et al.: Sonography and clinical outcome of viable hydatid liver cysts treated with double percutaneous aspiration and ethanol injection as first-line therapy: efficacy and long-term follow-up. AJR Am J Roentgenol. 2009; 193: W186-92.

7. Kim DW, Rho MH, Kim HJ, Kwon JS, Sung YS, Lee SW: Percutaneous ethanol injection for benign cystic thyroid nodules: is aspiration of ethanolmixed fluid advantageous? AJNR Am J Neuroradiol. 2005; 26: 2122-7.

8. Juliano RV, Nascimento FJ, Neto ACL, Borelli M, Wroclawski ER, et al: Tratamento não cirúrgico da hidrocele e cisto de cordão por escleroterapia com álcool absoluto. J Br Urol. 1998; 24: 254-7.

9. Altman DG: Practical statistics for medical research. London, Chapman \& Hall / CRC. 1991; pp. 325-36.

10. Marc G: Surgical management of male infertility and the other scrotal disorder in Campbell's urology. In: Walsh PC, Retik AB, Vaughan ED et al.: Philadelphia, Saunders. 2002; pp. 1579.

11. Shan CJ, Lucon AM, Arap S: Comparative study of sclerotherapy with phenol and surgical treatment for hydrocele. J Urol. 2003; 169: 1056-9.

12. Breda G, Giunta A, Gherardi L, Xausa D, Silvestre P, Tamai A: Treatment of hydrocele: randomised prospective study of simple aspiration and sclerotherapy with tetracycline. Br J Urol. 1992; 70: 76-7.

13. Ali J, Anwar W, Akbar M, Akbar SA, Zafar A: Aspiration and tetracycline sclerotherapy of primary vaginal hydrocoele of testis in adults. J Ayub Med Coll Abbottabad. 2008; 20: 93-5.

14. Ozkan S, Bircan K, Ozen H: Treatment of testicular hydrocele with tetracycline sclerotherapy. Int Urol Nephrol. 1990; 22: 67-9.

15. Testut L, Latarjet A: Tratado de Anatomia Humana. 1977; 1032-45. 
16. Saber A: New Minimally Access Hydrocelectomy. Urology. 2010; 14. [Epub ahead of print]

17. Onol SY, Ilbey YO, Onol FF, Ozbek E, Arslan B, Akbas A: A novel pull-through technique for the surgical management of idiopathic hydrocele. J Urol. 2009; 181: 1201-5.

18. Musa MT, Fahal AH, el Arabi YE: Aspiration sclerotherapy for hydroceles in the tropics. $\mathrm{Br} \mathrm{J}$ Urol. 1995; 76: 488-90.

19. Tammela TL, Hellström PA, Mattila SI, Ottelin PJ, Malinen LJ, Mäkäräinen HP: Ethanolamine oleate

Correspondence address:

Dr. Chen Jen Shan

Rua Castro Alves, 601 / 71

São Paulo, SP, 01532-001, Brazil

Fax: + 5511 3069-8081

E-mail: c_jen_shan@yahoo.com

\section{EDITORIAL COMMENT}

In this article, Chen JS et al. tried to study the efficacy of sclerosis of the tunica vaginalis with $99.5 \%$ alcohol regarding the cure rate of hydroceles and spermatoceles, post- procedural pain, hematoma, infection and effect on spermatogenesis. They found that this procedure is of great efficiency, easy application, economic, with few collateral effects and which may be applied to persons who have not yet constituted their families.

Aspiration of the hydrocele fluid and sclerotherapy may be simple, safe and inexpensive, but less effective than hydrocelectomy regarding patient satisfaction and the overall success rate (1). Many sclerosing agents have been used, such as Tetradecyl sodium sulfate, Tetracycline, adhesive fibrin, Quinacrine, Polidocanol, absolute alcohol and talc powder. However, the results have been inconsistent (2).

Standard hydrocelectomy may cause postoperative discomfort, temporary limitation of nor- sclerotherapy for hydroceles and spermatoceles: a survey of 158 patients with ultrasound followup. J Urol. 1992; 147: 1551-3.

20. Rencken RK, Bornman MS, Reif S, Olivier I: Sclerotherapy for hydroceles. J Urol. 1990; 143: 940-3.

21. Miskowiak J, Christensen AB: Treatment of hydrocele testis by injection of tetracycline. Eur Urol. 1988; 14: 440-1.

22. Osegbe DN: Fertility after sclerotherapy for hydrocele. Lancet 1991; 337: 172.

Accepted after revision:

November 16, 2010

mal activities and complications, such as hematoma, infection, persistent swelling, chronic pain and decreased fertility (3).To avoid these postoperative discomfort, the pull-through technique advocated by Onol et al., enables the surgeon to remove large hydrocele sacs through a small incision and with minimal dissection under direct vision of the testicular structures (3). A new minimally access hydrocelectomy through $2 \mathrm{~cm}$ scrotal skin incision and excision only of disc of the parietal tunica vaginalis about double of the skin incision dimension was recently published with encouraging outcome (4).

Finally, Hydrocelectomy is practiced as the gold standard technique for the treatment of hydrocele worldwide. Aspiration and sclerotherapy is cheap, less invasive and safe compared to hydrocelectomy. However, the outcomes are inconsistent because of lack of uniformity in methods and sclerosing agents used (5). So, Aspiration and sclerotherapy is a viable first-line therapeutic option in the management of hydroceles (1). 


\section{REFERENCES}

1. Beiko DT, Kim D, Morales A: Aspiration and sclerotherapy versus hydrocelectomy for treatment of hydroceles. Urology. 2003; 61: 708-12.

2. Shan CJ, Lucon AM, Arap S: Comparative study of sclerotherapy with phenol and surgical treatment for hydrocele. J Urol. 2003; 169: 1056-9.

3. Onol SY, Ilbey YO, Onol FF, Ozbek E, Arslan B, Akbaş A: A novel pull-through technique for the sur- gical management of idiopathic hydrocele. J Urol. 2009; 181: 1201-5.

4. Saber A: New Minimally Access Hydrocelectomy. Urology. 2010; 14. [Epub ahead of print]

5. Khaniya S, Agrawal CS, Koirala R, Regmi R, Adhikary S: Comparison of aspiration-sclerotherapy with hydrocelectomy in the management of hydrocele: a prospective randomized study. Int J Surg. 2009; 7: 392-5.
Dr. Aly Saber

Consultant Surgeon

Port-Fouad general hospital

Port-Fouad, Port-Said, Egypt

E-mail: alysaber54@gmail.com 